\title{
The Pressure Influence on the Properties of $S$-Phase Coatings Deposited by Reactive Magnetron Sputtering
}

\author{
S. FRYSKA* AND J. BARANOWSKA \\ West Pomeranian University of Technology, Szczecin, Poland
}

\begin{abstract}
Reactive magnetron sputtering of austenitic stainless steel in nitrogen containing atmosphere was used to deposit coatings composed of $S$-phase. The process was conducted at constant temperature $\left(200^{\circ} \mathrm{C}\right)$. The influence of total and partial nitrogen pressure on coating characteristics was investigated. It was observed that both total and nitrogen partial pressures have influence on coating composition and microstructure. Increasing nitrogen content in the $S$-phase coating can have a beneficial effect on its corrosion characteristics. It was also found that coatings deposited in the ambient of high nitrogen contents are composed of $S$-phase and the additional high-nitrogen phase, which is of crucial influence on mechanical properties of the coatings. It was also found that partial argon pressure can contribute to the changes in mechanical properties of the coatings.
\end{abstract}

DOI: 10.12693/APhysPolA.123.854

PACS: 81.15.-z, 68.60.-p, 68.60.Bs, 68.55.J-

\section{Introduction}

Austenitic stainless steel is widely used in many industrial applications, especially in those where good corrosion resistance is necessary. However, relatively low hardness and wear resistance largely reduce its applicability. Therefore, intensive research and technological work on increasing mechanical properties of stainless steel without affecting its corrosion resistance has been conducted for many years. The so-called low temperature nitriding process is especially promising in this respect. It was found that if the nitriding process is conducted at the temperature below $500^{\circ} \mathrm{C}$, the new phase (so-called $S$-phase) is formed [1-5], which is considered to be a supersaturated nitrogen solution in the austenitic matrix. This phase is very hard and exhibits corrosion resistance comparable or even better than the austenitic matrix $[1,4]$. $S$-phase can be produced by reactive sputtering deposition. Very low temperature of deposition (even below $300^{\circ} \mathrm{C}$ ), which reduces the risk of phase decomposition, is one of the main advantages of this technology. Not numerous studies concerning this process can be found [6-11]. They are mainly concentrated on microstructural aspects of coating growth. The main objective of this study was to investigate influence of nitrogen content in the $S$-phase on its mechanical and corrosion characteristics. Nitrogen content was controlled by means of variation in the total and nitrogen partial pressures.

\section{Experimental}

$S$-phase coatings were deposited on stainless steel and silicon substrates by reactive magnetron sputtering deposition. The stainless steel substrates were mechanically ground and polished to obtain the surface rough-

*corresponding author; e-mail: Sebastian.Fryska@zut.edu.pl ness of $0.007 \mu \mathrm{m}$. Before the deposition the substrates were cleaned by means of $10 \mathrm{~min}$ ions bombardment at the pressure of $2.66 \mathrm{~Pa} .2 \mathrm{~W}$ of power bias was applied during this process. Two $50 \mathrm{~mm}$ diameter targets made of X10CrNi18-10 stainless steel were used for coating deposition. The targets were powered using $750 \mathrm{~W}$ and $20 \mathrm{kHz}$ pulsed dc supply at a constant target power of $200 \mathrm{~W}(\approx 0.3 \mathrm{~A})$. The chamber was pumped down by a turbo pump to a base pressure of about $10^{-5} \mathrm{~Pa}$. The pressure was measured using a MKS Barotron (capacitance manometer) gauge, and the inlet gas was controlled by the MKS Mass-Flo controller. The constant temperature of $200{ }^{\circ} \mathrm{C}$ was maintained during the process. The coatings were deposited for $30 \mathrm{~min}$.

The deposition parameters.

TABLE

\begin{tabular}{c|c|c|c|c}
\hline \hline $\begin{array}{c}\text { Sample } \\
\text { No. }\end{array}$ & $\begin{array}{c}\text { Total } \\
\text { pressure } \\
{[\mathrm{Pa}]}\end{array}$ & $\begin{array}{c}\mathrm{Ar} / \mathrm{N}_{2} \text { flow } \\
\text { ratio }\end{array}$ & $\begin{array}{c}p_{\mathrm{N} 2} \\
{[\mathrm{~Pa}]}\end{array}$ & $\begin{array}{c}\mathrm{N}_{2} \\
{[\%]}\end{array}$ \\
\hline $1 a$ & 0.53 & $10 / 3$ & 0.12 & 23 \\
$1 b$ & 0.8 & $11 / 2$ & 0.12 & 15 \\
$1 c$ & 1.06 & $11.5 / 1.5$ & 0.12 & 11.5 \\
$2 a$ & 0.53 & $6.5 / 6.5$ & 0.26 & 50 \\
$2 b$ & 0.8 & $8.7 / 4.3$ & 0.26 & 33 \\
$2 c$ & 1.06 & $9.75 / 3.25$ & 0.26 & 25 \\
$3 a$ & 0.53 & $3 / 10$ & 0.4 & 77 \\
$3 b$ & 0.8 & $6.5 / 6.5$ & 0.4 & 50 \\
$3 c$ & 1.06 & $8 / 5$ & 0.4 & 38.5
\end{tabular}

The total pressure, argon to nitrogen flow ratio and nitrogen partial pressure are shown in Table. Nitrogen partial pressure was calculated from the total pressure and flows ratio of technological gases.

The coatings were characterized by means of the following techniques:

1. Scanning electron microscope (SEM) (Hitachi SU-70) and atomic force microscope (AFM) (Nanoscope IV - Veeco) were used to investigate microstructure of the coatings; 
2. X-ray diffraction (XRD) with the Bragg-Brentano geometry for the range of 2 theta angles between $35-140^{\circ}$ was used to investigate phase composition of the coatings. Co $K_{\alpha}$ radiations (X'pert Panalytical);

3. Electron microprobe spectrometry (EPMS WDS) was applied to measure nitrogen content in the coatings (Thermo Scientific, accelerating voltage $5 \mathrm{kV}$, beam current $11 \mathrm{nA})$;

4. Hardness measurements were done by nanoindentation with a Berkovich tip (XP - NanoInstruments). The continuous stiffness measurement technique was applied to determine the hardness changes across the coatings. The load was increased to get a maximum penetration depth of $c a$. $2.9 \mu \mathrm{m}$. The maximum load of $490-545 \mathrm{mN}$ was reached. The set of 25 indents was applied to each coating. Coatings' hardness was calculated on the basis of the values obtained for $c a .100 \mathrm{~nm}$ indenter penetration only;

5. Stationary corrosion potentials were measured in $3 \% \mathrm{NaCl}$ solution; against the calomel electrode for $1 \mathrm{~h}$ (Atlas 9833);

6. Coating thickness was estimated by means of a profilometer (Dektak $6 \mathrm{M}$ - Veeco) by measuring the step between the coating and uncoated part of the substrate which remained covered during deposition.

\section{Results and discussion}

The SEM observations revealed characteristic columnar structure of the coatings of the thickness in the range of $270-470 \mathrm{~nm}$. All the coatings, independently of the deposition parameters used in experiments, showed a microstructure similar to that shown in Fig. 1. An AFM investigation of coating surfaces confirmed the submicron size of grains formed in all the coatings (Fig. 2).

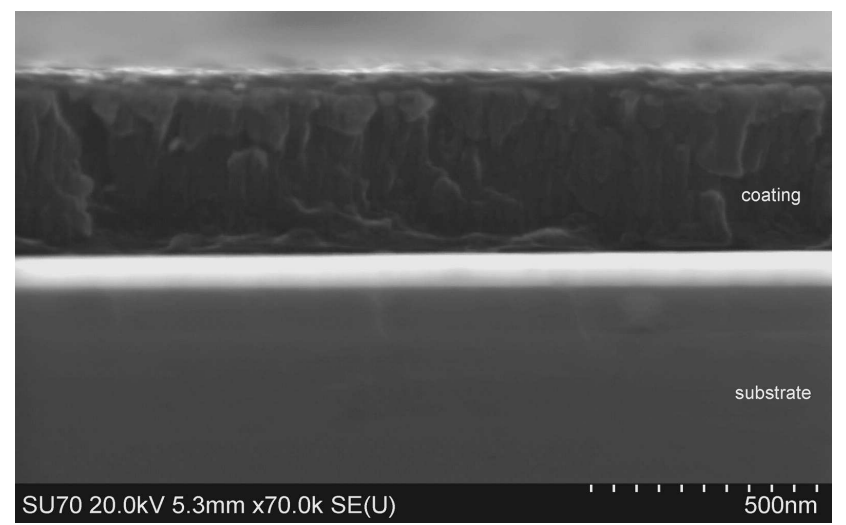

Fig. 1. SEM image of the fracture of the coating $2 a$.
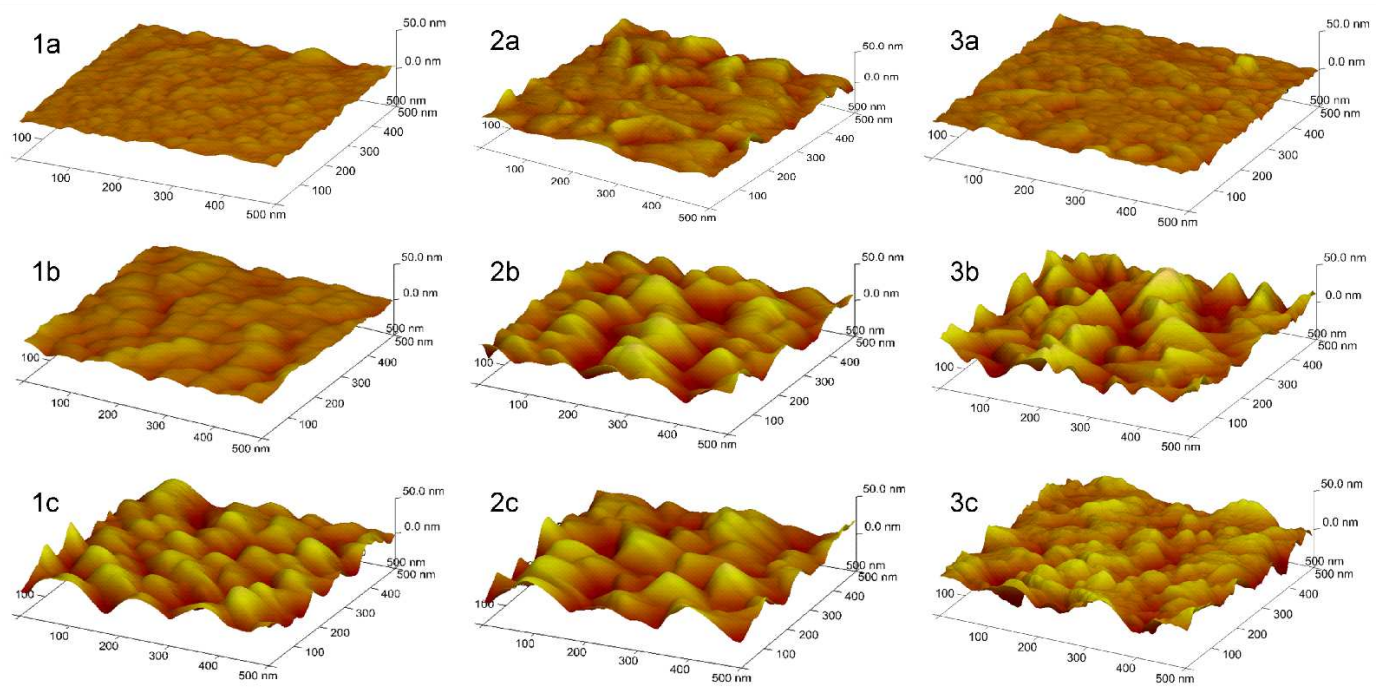

Fig. 2. AFM pictures of coatings topography.

Roughness of the surface was slightly affected by changes in the nitrogen partial pressure. Total pressure has small influence on surface roughness. The roughness was the lowest for the coatings obtained at the lowest total pressure. Further increase of the pressure led to an increase in coating roughness and grains size (Fig. 2). This observation is in agreement with the Thornton model of microstructure formation in the deposited coatings [12].

Figure 3 presents the X-ray diffraction patterns of the coatings. $S$-phase peaks are clearly identified in the diffraction pattern of the coatings obtained in the atmosphere with a higher nitrogen content (coatings $2 a^{-} c$ 


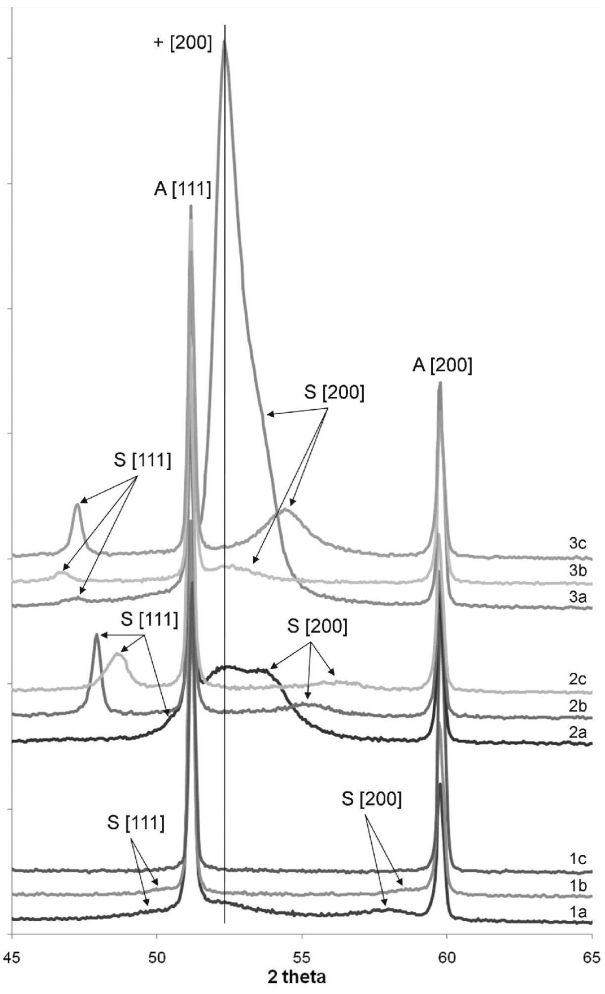

Fig. 3. Diffraction patterns of the coatings investigated in the experiments: A - austenite, $\mathrm{S}-S$-phase, + - an unidentified peak, XRD, Co $K_{\alpha}$.

and $3 a-c)$. For the coatings deposited in the nitrogen-poor atmosphere (coatings $1 a-c$ ) $S$-phase peaks intensity was very low. But their presence was additionally confirmed by the grazing angle X-ray diffraction done on the coatings deposited on the $\mathrm{Si}$ substrates. It was found that the $S$-phase peaks were located very close to the austenite peaks positions. Nitrogen content in the $S$-phase can vary in a very wide range of concentrations (10-50 at.\% [13]), which have an influence on the lattice parameter of this phase. The higher nitrogen content in the $S$-phase, the more shifted their peaks towards smaller 2 theta angles (the higher lattice parameter). This relation was also observed in the coatings under investigations. It could be assumed that mechanical properties of $S$-phase coatings were clearly dominated by the presence of this unidentified phase. Small nitrogen content dependence of mechanical properties can be observed within each group of coatings (1,2 and 3). Those deposited at the lowest total pressure are always characterized by the highest hardness and the Young modulus (Fig. 4a).

Texture changes can be observed depending on the deposition conditions. Strong $\langle 100\rangle$ texture is formed in the coatings deposited in the nitrogen-rich atmosphere (Fig. 3 - coatings $2 a$ and $3 a$ ). The others are composed of the grains with more versatile orientation (Fig. 3).

In the diffraction patterns of the coatings obtained in atmospheres containing a high nitrogen content (coatings
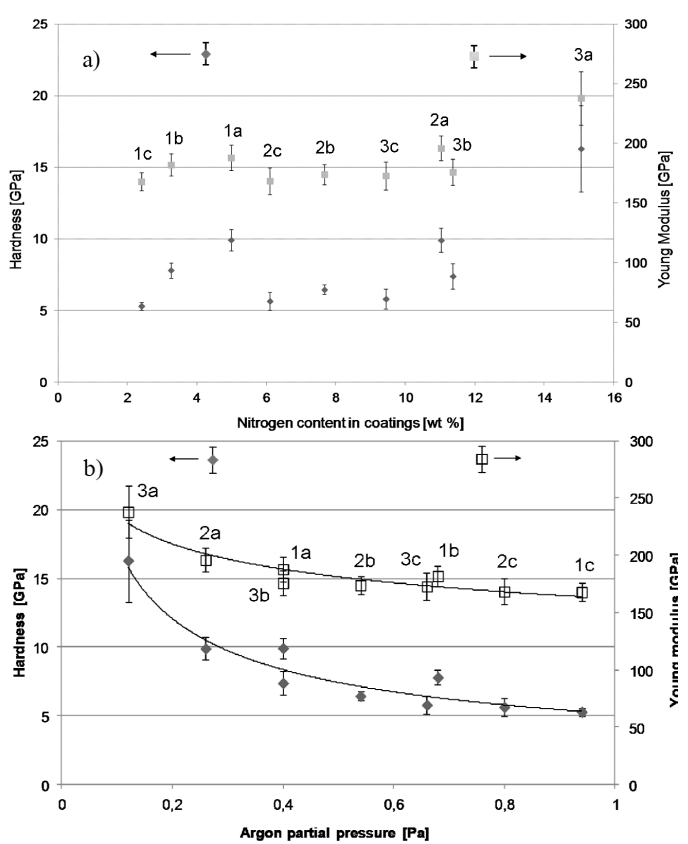

Fig. 4. Hardness and the Young modulus of the coatings depending on: (a) nitrogen concentration, (b) argon partial pressure.

$2 a, 3 a$ and $b$ ) the additional peak can be detected for 2 theta angle of about $52^{\circ}$ (marked with cross in Fig. 3 ). This peak can be attributed to formation of nonstoichiometric CrN [14] but this statement needs further investigations.

The results of hardness measurement are presented in Fig. 4. The absolute values of coatings' hardness are relatively low in comparison with the data presented in literature for the $S$-phase coatings $[7,8]$. This is due to the fact that thickness of the layers is relatively low. The hardness was evaluated based on the measurements obtained for the indenter penetration of about $100 \mathrm{~nm}$ (one fourth of coating thickness). Under such conditions hardness measurements are underestimated due to the strong influence of soft substrate. However, the coatings have comparable layer thickness and therefore relative hardness of these coatings can be discussed.

No clear relationship between the hardness and the nitrogen content was observed (Fig. 4). However, looking more closely at these results, one can observe that coatings $1 b, 1 c, 2 b, 2 c, 3 b$, and $3 c$ have the lowest hardness. These coatings are characterized by various orientations of the grains they are built of (Fig. 3). Coatings 1a, $2 a$, and $3 a$ have the highest hardness. The presence of unidentified phase was detected in those coatings and what is symptomatic, coating $3 a$ which is dominated by this phase exhibits almost 3 times higher hardness than other coatings.

Similar observation can be done for the Young modulus, which is clearly very much different for coating $3 a$ (Fig. 4a) from the other coatings. 
It can be observed that mechanical properties have well pronounced dependence on partial argon pressure (Fig. 4b). According to the Thornton model, total pressure and temperature are the main parameters influencing the type of microstructure to be formed. High deposition pressure usually leads to formation of porous microstructure, while dense and compact microstructure is formed at low pressure thanks to the intense resputtering process. This latter effect enables coatings with better mechanical properties to be formed. From the presented results it can be concluded that argon pressure is a crucial parameter contributing to the resputtering effect responsible for such a compact microstructure formation.

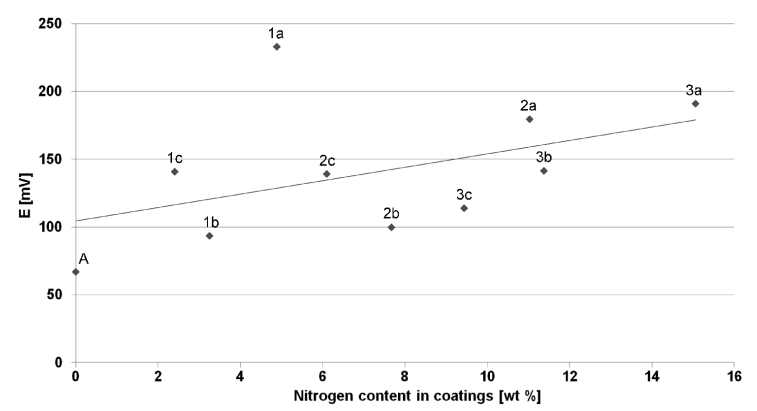

Fig. 5. Stationary corrosion potential of the coatings in function of nitrogen concentration: A - austenite potential.

Potentiostatic tests revealed very good corrosion behaviour of all the coatings. Their stationary corrosion potentials are higher than that of austenite (Fig. 5). This is in a good agreement with other investigations [15, 16]. It can be also found that the stationary corrosion potential increases along with the increasing nitrogen content in the coatings, which confirmed the observations presented by Dahm et al. [17].

\section{Summary}

During reactive magnetron sputtering of stainless steel it is possible to obtain coatings composed of $S$-phase, which are characterized by good mechanical and corrosion properties. Both the total and nitrogen partial pressure have influence on coating composition and microstructure. Increasing nitrogen content in the $S$-phase coating can have a beneficial effect on its corrosion characteristics. Mechanical properties can be significantly improved by the presence of unidentified phase, whose occurrence was observed in the nitrogen-rich $S$-phase coatings. There is no clear dependence between hardness and nitrogen content in the coatings. However, it was observed that mechanical properties increased along with the decreasing partial argon pressure in working atmosphere.

\section{References}

[1] K. Ichii, K. Fujimura, T. Takase, Tech. Rep. Kansai Univ. 27, 135 (1986).

[2] J. Baranowska, Surf. Coat. Technol. 180-181, 145 (2003).

[3] Th. Christiansen, M.A.J. Somers, Struers J. Metallogr. 9, 1 (2006).

[4] C.X. Li, T. Bell, Corrosion Sci. 46, 1527 (2004).

[5] M.P. Fewell, D.R.G.J.M. Mitchell Priest, K.T. Short, G.A. Collins, Surf. Coat. Technol. 131, 300 (2000).

[6] X.Y. Li, Y.Sun, T. Bell, Z. Metallkd. 90, 901 (1999).

[7] K.L. Dahm, P.A. Dearnley, Proc. Inst. Mech. Eng. L; J. Mater.: Design Appl. 214, 181 (2000).

[8] A. Saker, H. He, T. Czerwiec, X. Li, L. Tran Huu, C. Dong, H. Michel, C. Frantz, Thin Solid Films 516, 1029 (2008).

[9] G. Terwagne, J. Colaux, D.R. Mitchell, K.T. Short, Thin Solid Films 469-470, 167 (2004).

[10] S.R. Kappaganthu, Y. Sun, J. Cryst. Growth 267, 385 (2004).

[11] K.L. Dahm, P.A. Dearnley, Surf. Eng. 12, 61 (1996).

[12] J.A. Thornton, J. Vac. Sci. Technol. A 4, 3059 (1986).

[13] J. Baranowska, Low temperature nitriding of stainless steel, WN Politechniki Szczecińskiej, Szczecin 2007 (in Polish).

[14] Z.B. Zhao, Z.U. Rek, Z.M. Yalisove, J.C. Billelo, Surf. Coat. Technol. 185, 329 (2004).

[15] J. Baranowska, S. Fryska, J. Przekop, T. Suszko, Adv. Manuf. Sci. Technol. 33, 59 (2009).

[16] S. Inoue, T. Saeki, H. Uchida, K. Koterazawa, M. Iwasa, Vacuum 66, 257 (2002).

[17] K.L. Dahm, A.J. Betts, P.A. Dearnley, Surf. Eng. 26, $271(2010)$. 